RASĀYAN J. Chem.

Vol. 12 | No. 4 |2235 - 2240| October - December | 2019 ISSN: 0974-1496 | e-ISSN: 0976-0083 | CODEN: RJCABP

\title{
EVALUATION OF HEAVY METALS TOXICITY IN THE GROUNDWATER OF SOME VILLAGES OF SIRSA DISTRICT OF HARYANA, INDIA
}

\author{
Parul Kumar $^{1, *}$, Sushma Jain ${ }^{1}$ and Bhupender Kumar ${ }^{2}$ \\ ${ }^{1}$ P.G. Department of Chemistry, Government Dungar College, \\ Bikaner- 334003 (Rajasthan) India \\ ${ }^{2}$ Department of Chemistry, Central University of Punjab, \\ Bathinda- 151001 (Punjab) India \\ *E-mail: parulsardana3@gmail.com
}

\begin{abstract}
An attempt was made to assess the groundwater quality in some rural parts of Sirsa district of Haryana, India with respect to heavy metals contamination. For this purpose, 23 groundwater samples were collected from the bore wells during pre-monsoon in 2017 from some selected locations in the study area where the groundwater is used for drinking and agricultural activities. The samples have been analyzed for seven heavy metals viz. Mn, As, $\mathrm{Zn}, \mathrm{Cd}$, $\mathrm{Pb}, \mathrm{Cu}$ and $\mathrm{Cr}$ using ICP-MS. The results were compared with the BIS standards to assess the suitability of groundwater for drinking. To assess the heavy metal contamination, the heavy metal pollution index (HPI), metal index (MI) and hazard index (HI) was calculated. The groundwater with $\mathrm{HI}>1$ falls in the high pollution category. In our study, 10 out of 23 samples were not fit to consume by the infants and all the 23 samples were found to be unfit for both the children and the adults. The correlation matrix showed a good correlation of HPI with Mn ( $\mathrm{r}=$ 0.998), As ( $\mathrm{r}=0.993), \mathrm{Cu}(\mathrm{r}=0.998), \mathrm{Cr}(\mathrm{r}=0.998)$ and with $\mathrm{Pb}(\mathrm{r}=0.998)$ whereas the correlation of MI with Mn $(\mathrm{r}=0.998), \mathrm{As}(\mathrm{r}=0.994), \mathrm{Cu}(\mathrm{r}=0.998), \mathrm{Cr}(\mathrm{r}=0.999)$ and with $\mathrm{Pb}(\mathrm{r}=0.998)$.
\end{abstract}

Keywords: Ground Water, Heavy Metal Pollution Index, Metal Index, Hazard Index, Sirsa, Haryana.

CRASĀYAN. All rights reserved

\section{INTRODUCTION}

Water is the most important source of life on this planet. It is the chief constituent of all the plants, animals, many other organisms and mankind for their survival in the biosphere. ${ }^{1}$ Groundwater is one of the major sources of fresh natural water which is being used for both domestic and irrigation purposes worldwide. In India, 90\% rural and 30\% of the urban population is totally dependent upon groundwater for drinking and domestic activities. ${ }^{2,3}$ In comparison to surface water, the groundwater is generally considered to be free from contaminants because of its infiltration by soil media. ${ }^{4}$ Heavy metals are very common environmental pollutants and their presence in water is through many anthropogenic and natural activities. ${ }^{5,6}$

The water contaminated by heavy metals is unfit for drinking use. ${ }^{7}$ The behavior of heavy metals in aquifers depends on the lithology, bio-geochemical processes and the source of water. ${ }^{8}$ Several studies proposed the occurrence of heavy metals in groundwater by the excessive use of fertilizers and pesticides, solid waste dumping, untreated and pesticides, solid waste dumping, untreated industrial wastes, mine drainage etc. ${ }^{9-11}$

The heavy metal pollution of groundwater is a serious health problem all over the world due to its accumulation ${ }^{11}$. To avoid health problems, regular monitoring of heavy metals concentration is necessary. So, it becomes more important to find out the degree of heavy metal pollution and its impacts on the ecosystem and on health. To get the overall influence of Pollution, Quality, Indices are useful. The heavy metal pollution index (HPI) has been used to determine the heavy metal Pollution of ground and the surface water. ${ }^{12,13}$

Rasayan J. Chem., 12(4), 2235-2240(2019)

http://dx.doi.org/10.31788/RJC.2019.1245259

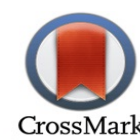


RASĀYAN J. Chem.

Vol. 12 | No. 4 | 2235 - 2240| October - December | 2019

The metal index (MI) gives the possible additive effect of heavy metals on health and the overall drinking water quality. The HPI, MI and the non-carcinogenic risk assessment for the groundwater of some villages of Sirsa district were determined in the present study.

\section{EXPERIMENTAL}

All the heavy metals like Cadmium $(\mathrm{Cd})$, Copper $(\mathrm{Cu})$, Manganese $(\mathrm{Mn})$, Arsenic (As) Leab $(\mathrm{Pb})$, Chromium (Cr) and Zinc (Zn) were determined using ICP-MS and the data were used for the calculations. A total of 23 samples were collected from different villages of Sirsa district of Haryana state for the study. SPSS 16.0 software was used for statistical analysis. Microsoft Excel 2007 was used to draw various graphs.

Calculation of HPI: The HPI was calculated using the formula ${ }^{12}$ :

$$
\begin{aligned}
& \mathrm{HPI}=\sum_{\mathrm{i}=1}^{\mathrm{n}} \frac{\mathrm{WiQi}}{\sum_{\mathrm{i}=1}^{\mathrm{n}} \mathrm{Wi}} \\
& \text { and } \mathrm{Qi}=\sum_{\mathrm{i}=1}^{\mathrm{n}} \frac{|\mathrm{Mi}-\mathrm{Ii}|}{\mathrm{Si}-\mathrm{Ii}} \times 100
\end{aligned}
$$

Where wi stands for the unit weight of the ith component, $\mathrm{n}$ gives the number of parameters, Qi stands for the sub-index of the ith parameter, Mi is the observed value of the heavy metal in the analysis, Ii gives the ideal value for ith components and $\mathrm{Si}$ gives the standard value of the ith component. All the values are given in Table-1.

\begin{tabular}{c|c|c|c|c|c}
\multicolumn{7}{|c}{ Table-1 } \\
\hline $\begin{array}{c}\text { Heavy } \\
\text { Metal }\end{array}$ & $\begin{array}{c}\mathrm{Si} \\
(\mathrm{PPb})\end{array}$ & $\begin{array}{c}\mathrm{Ii} \\
(\mathrm{PPb})\end{array}$ & $\mathrm{Wi}$ & $\mathrm{MAC}^{16}$ & $\begin{array}{c}\mathrm{RfD}^{17,18} \\
(\mathrm{Mg} / \mathrm{Kg} / \mathrm{Day})\end{array}$ \\
\hline $\mathrm{Zn}$ & 1500 & 5000 & 0.000066 & 15000 & $3.0 \times 10^{-1}$ \\
\hline $\mathrm{Mn}$ & 300 & 100 & 0.0033 & 300 & $1.4 \times 10^{-1}$ \\
\hline $\mathrm{As}$ & 50 & -- & 0.02 & 50 & $3.0 \times 10^{-4}$ \\
\hline $\mathrm{Cd}$ & 10 & -- & 0.1 & 10 & $5.0 \times 10^{-4}$ \\
\hline $\mathrm{Cu}$ & 1500 & 50 & 0.0066 & 1500 & $5.0 \times 10^{-3}$ \\
\hline $\mathrm{Pb}$ & 50 & -- & 0.02 & 50 & $3.6 \times 10^{-3}$ \\
\hline $\mathrm{Cr}$ & 50 & -- & 0.02 & 50 & $3.0 \times 10^{-3}$ \\
\hline
\end{tabular}

The Metal index (MI) was calculated for each sample using the formula ${ }^{19}$

$$
M I=\sum_{i=1}^{n} \frac{C i}{(M A C)} \times 100
$$

MAC is the maximum allowable concentration of the ith component and $\mathrm{Ci}$ is the concentration of the ith component in the sample.

Hazard Index (HI) - The non-carcinogenic risk assessment due to the intake of heavy metals polluted groundwater was calculated by $\mathrm{HI}$ using the equation ${ }^{14}$ :

$\mathrm{LADD}=(\mathrm{C} \times \mathrm{IR} \times \mathrm{EF} \times \mathrm{FD}) /(\mathrm{AT} \times \mathrm{BW})$

Where,

LADD Lifetime average daily dose due to the intake of heavy metals by drinking in $\mathrm{mg} / \mathrm{kg} / \mathrm{day}$

IR Ingestion rate of water $(250 \mathrm{ml} /$ day for infants, $1.5 \mathrm{~L}$ for children and $3 \mathrm{~L}$ for adults)

C Concentration of heavy metal in the samples

ED Exposure duration (66.4 years)

EF Exposure frequency (days/year)

AT Average time (days)

BW Bodyweight (6.9 $\mathrm{kg}$ for infants, $18.7 \mathrm{~kg}$ for children and $57.5 \mathrm{~kg}$ for adults)

The Hazard Quotient (HQ) was calculated using equation ${ }^{14}: \mathrm{HQ}=\mathrm{LADD} / \mathrm{R} f \mathrm{D}$

$\mathrm{RfD}$ is the reference daily dose for oral exposure of heavy metal exposed to an individual ( $\mathrm{mg} / \mathrm{Kg} / \mathrm{day})$. 
RASĀYAN J. Chem.

Vol. 12 | No. 4 | 2235 - 2240| October - December | 2019

The non-carcinogenic risk assessment given by $\mathrm{HI}$ and $\mathrm{HI} \sum_{i=1}^{n} H Q_{i}$

Table-2 showing the maximum, minimum, mean, Std. deviation. All the concentrations are expressed in mg/l. NR means no relaxation, Dl means desirable limit and PL means permissible limit.

Table 2

\begin{tabular}{l|l|l|l|l|l}
\hline & $\begin{array}{l}\text { DL-PL } \\
(\mathrm{ppm})\end{array}$ & $\begin{array}{l}\text { Minimum } \\
(\mathrm{ppm})\end{array}$ & $\begin{array}{l}\text { Maximum } \\
(\mathrm{ppm})\end{array}$ & Mean & $\begin{array}{l}\text { Std. } \\
\text { Deviation }\end{array}$ \\
\hline $\mathrm{Mn}$ & $0.1-0.3$ & .00 & 1.03 & .0902 & .23069 \\
\hline $\mathrm{Cd}$ & $0.003-\mathrm{NR}$ & .00 & .00 & .0000 & .00000 \\
\hline $\mathrm{As}$ & $0.005-\mathrm{NR}$ & .00 & 1.05 & .0865 & .23329 \\
\hline $\mathrm{Cu}$ & $0.05-1.5$ & .00 & 1.02 & .0860 & .23214 \\
\hline $\mathrm{Cr}$ & $0.05-\mathrm{NR}$ & .00 & 1.03 & .0869 & .23169 \\
\hline $\mathrm{Pb}$ & $0.01-\mathrm{NR}$ & .00 & 1.00 & .0803 & .23408 \\
\hline $\mathrm{Zn}$ & $5-15$ & .02 & 4.69 & .4989 & .94142 \\
\hline $\mathrm{HPI}$ & & 1.58 & 789.28 & 73.8357 & 178.03014 \\
\hline $\mathrm{MI}$ & & .01 & 9.46 & .8080 & 2.13713 \\
\hline
\end{tabular}

\section{RESULTS AND DISCUSSION}

\section{Carcinogenic Risk Assessment}

The HPI value in the study area deviates from 1.50 to 789.28 for the seven heavy metals. The critical value of HPI is 100 . Four samples exceed the critical value of HPI, so these are not suitable for human consumption. The main crops cultivated in the study area are wheat, mustard, cotton, Barley, Bajra, Guvar and Channa. The farmers in the study area are using fertilizers, fungicides, pesticides to improve their crop yield. The accumulation of heavy metals is continued by leaching ${ }^{15}$. Groundwater classification on the basis of HPI and MI ${ }^{192}$. The HPI and MI for the samples are given in Table-3.

\begin{tabular}{c|c|c|c|c|c|c|c}
\hline \multicolumn{7}{|c|}{ Sable-3 } & MI \\
\hline S.No. & Sample No. & HPI & MI & S.No. & Sample No. & HPI & \\
\hline 1 & Nimla & 21.37 & 0.128 & 13 & Rania & 1.58 & 0.010 \\
\hline 2 & Bhuratwala & 6.39 & 0.053 & 14 & Nanuana & 16.43 & 0.065 \\
\hline 3 & Chaharwala & 13.06 & 0.128 & 15 & $\begin{array}{c}\text { Chattargarh } \\
\text { Patti }\end{array}$ & 30.74 & 0.212 \\
\hline 4 & $\begin{array}{c}\text { Kashi Ka } \\
\text { Bas }\end{array}$ & 4.86 & 0.049 & 16 & Rania & 14.59 & 0.096 \\
\hline 5 & $\begin{array}{c}\text { Sureran } \\
6\end{array}$ & 17.61 & 0.106 & 17 & $\begin{array}{c}\text { Ahmadpur } \\
\text { Road }\end{array}$ & 3.92 & 0.038 \\
\hline 7 & $\begin{array}{c}\text { Poharka } \\
\text { Khera }\end{array}$ & 19.45 & 0.091 & 18 & Rania & 18.02 & 0.180 \\
\hline 9 & Rania & 6.92 & 0.050 & 20 & Gudia Khera & 105.55 & 1.152 \\
\hline 10 & Rania & 25.49 & 0.168 & 21 & Shahpuria & 100.36 & 1.020 \\
\hline 11 & Kakriawali & 3.50 & 0.038 & 22 & Ganja Rupana & 413.80 & 4.81 \\
\hline & Road & 6.01 & 0.059 & 23 & $\begin{array}{c}\text { Rupana } \\
\text { Bishnoia }\end{array}$ & 789.28 & 9.463 \\
\hline
\end{tabular}

Table-4

\begin{tabular}{c|c|c|c}
\hline HPI & Pollution level & No. of Sample & Samples \\
\hline$<15$ & Low & 10 & $2,3,4,8,10,11,12,13,16,17$ \\
\hline $15-30$ & Medium & 7 & $1,5,6,7,9,14,18$ \\
\hline$>30$ & High & 6 & $15,19,20,21,22,23$ \\
\hline
\end{tabular}


RASĀYAN J. Chem.

Vol. 12 | No. 4 | 2235 - 2240| October - December | 2019

Table-5

\begin{tabular}{c|c|c|c}
\hline MI & Class of water & No. of Samples & Sample \\
\hline$<0.3$ & Very pure & 18 & $1,2,3,4,5,6,7,8,9,10$ \\
& & & $11,12,13,14,15,16,17,18$ \\
\hline $0.3-1.0$ & Pure & 1 & 19 \\
\hline $1.0-2.0$ & Slightly affected & 2 & $20-21$ \\
\hline $2.0-4.0$ & Moderately affected & Nil & Nil \\
\hline $4.0-6.0$ & Strongly affected & 1 & 22 \\
\hline$>6.0$ & Seriously affected & 1 & 23 \\
\hline
\end{tabular}

\section{Non - carcinogenic Risk Assessment}

The non-carcinogenic risk was calculated using the Hazard Index (HI) for all the seven heavy metals. For the $\mathrm{HI}<1$, water is supposed to be safe and for $\mathrm{HI}>1$, it indicates risk ${ }^{15}$. The HI value for infants, children and adults is given in Table-6. Graphs showing (Fig.-1) the variation of HI for infants, children and adults:
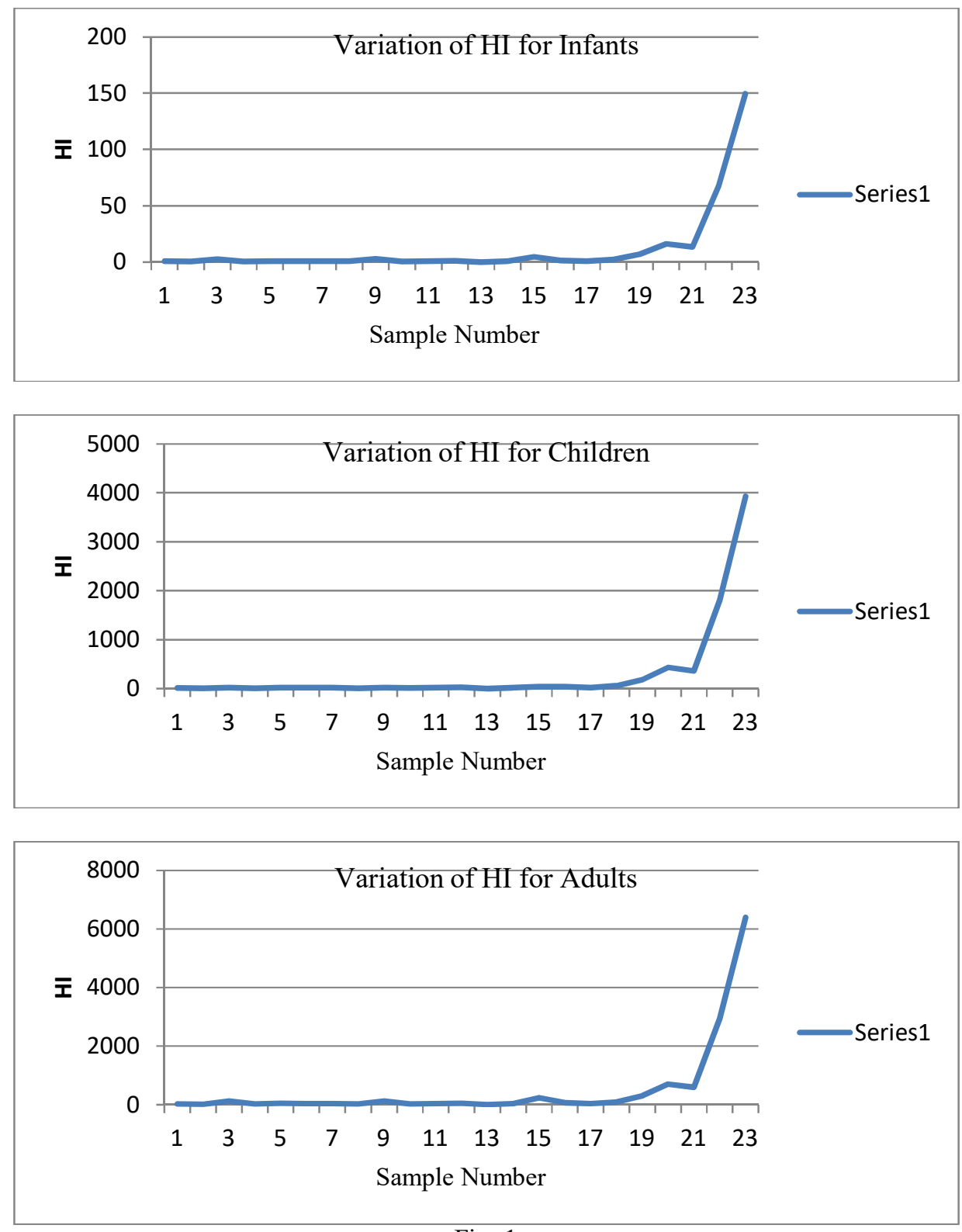

Fig.-1 
RASĀYAN J. Chem.

Vol. 12 | No. 4 |2235 - 2240| October - December | 2019

Table-6

\begin{tabular}{c|c|c|c|c}
\hline \multirow{2}{*}{ S.No. } & \multirow{2}{*}{ Sample No. } & \multicolumn{3}{|c}{ HI } \\
\cline { 3 - 5 } & & Infants & Children & Adults \\
\hline 1 & Nimla & 0.69 & 15.87 & 25.70 \\
\hline 2 & Bhuratwala & 0.49 & 10.78 & 14.33 \\
\hline 3 & Chaharwala & 2.55 & 20.44 & 115.70 \\
\hline 4 & Kashi Ka Bas & 0.54 & 11.94 & 18.23 \\
\hline 5 & Sureran & 0.89 & 24.69 & 41.19 \\
\hline 6 & Poharka & 0.82 & 23.86 & 36.30 \\
\hline 7 & Mehna Khera & 0.84 & 22.42 & 37.68 \\
\hline 8 & Rania & 0.81 & 11.15 & 17.44 \\
\hline 9 & Rania & 2.65 & 21.68 & 117.50 \\
\hline 10 & Bakriawali & 0.50 & 14.81 & 23.19 \\
\hline 11 & Kelnia Road & 0.68 & 19.41 & 32.0 \\
\hline 12 & Rampur Their & 1.03 & 28.15 & 42.90 \\
\hline 13 & Rania & 0.09 & 1.89 & 2.93 \\
\hline 14 & Nanuana & 0.74 & 21.0 & 33.96 \\
\hline 15 & Chattargarh Patti & 4.82 & 41.65 & 234.54 \\
\hline 16 & Rania & 1.50 & 41.86 & 67.04 \\
\hline 17 & Ahmadpur Road & 0.75 & 21.31 & 35.0 \\
\hline 18 & Rania & 2.19 & 60.04 & 87.42 \\
\hline 19 & Bakriawali & 6.83 & 185.63 & 298.51 \\
\hline 20 & Gudia Khera & 16.20 & 431.74 & 699.37 \\
\hline 21 & Shahpuria & 13.45 & 363.85 & 589.92 \\
\hline 23 & Ganja Rupana & 67.65 & 1809.47 & 2944.28 \\
\hline & Rupana Bishnoia & 149.50 & 3933.0 & 6396.38 \\
\hline & & & &
\end{tabular}

Correlation Matrix

To find out the relationship among various heavy metals, Pearson's correlation matrix was used. A good positive correlation was observed between all the heavy metals except with $\mathrm{Cd}$ and $\mathrm{Zn}$.

Table-7

\begin{tabular}{l|l|l|l|l|l|l|l|l|l}
\hline & $\mathrm{Mn}$ & $\mathrm{Cd}$ & $\mathrm{As}$ & $\mathrm{Cu}$ & $\mathrm{Cr}$ & $\mathrm{Pb}$ & $\mathrm{Zn}$ & $\mathrm{HPI}$ & $\mathrm{MI}$ \\
\hline $\mathrm{Mn}$ & 1 & $\cdot^{\mathrm{a}}$ & $.993^{* *}$ & $.997^{* *}$ & $.998^{* *}$ & $.994^{* *}$ & .137 & $.998^{* *}$ & $.998^{* *}$ \\
\hline $\mathrm{Cd}$ & & $\cdot^{\mathrm{a}}$ &.$^{\mathrm{a}}$ &.$^{\mathrm{a}}$ &.$^{\mathrm{a}}$ &.$^{\mathrm{a}}$ &.$^{\mathrm{a}}$ &.$^{\mathrm{a}}$ &.$^{\mathrm{a}}$ \\
\hline $\mathrm{As}$ & & & 1 & $.992^{* *}$ & $.993^{* *}$ & $.988^{* *}$ & .093 & $.993^{* *}$ & $.994^{* *}$ \\
\hline $\mathrm{Cu}$ & & & & 1 & $.997^{* *}$ & $.995^{* *}$ & .097 & $.998^{* *}$ & $.998^{* *}$ \\
\hline $\mathrm{Cr}$ & & & & & 1 & $.996^{* *}$ & .084 & $.998^{* *}$ & $.999^{* *}$ \\
\hline $\mathrm{Pb}$ & & & & & & 1 & .089 & $.998^{* *}$ & $.998^{* *}$ \\
\hline $\mathrm{Zn}$ & & & & & & & 1 & .097 & .102 \\
\hline $\mathrm{HPI}$ & & & & & & & & 1 & $1.000^{* *}$ \\
\hline $\mathrm{MI}$ & & & & & & & & & 1 \\
\hline
\end{tabular}

\section{CONCLUSION}

The heavy metal pollution indices and statistical methods were used to assess the groundwater quality in a highly cultivated area of the Sirsa district of Haryana state. The presence of heavy metals in groundwater was found to be due to agricultural activities mainly. The health risk due to heavy metals was ascertained by calculating HPI, MI and HI for infants, children and adults. HPI indicates that 10 samples have a low level of pollution index, 7 have a medium level and 6 have a high level of a pollution index. The MI value indicates that 18 samples are very pure, 1 is pure, 2 are slightly affected, 1 is strongly affected and 1 is seriously affected. The HI values indicate that 10 samples are not fit to consume by the infants and all the 23 samples are not suitable to consume by the children and the adults. The groundwater in the study area is contaminated by heavy metals and so immediate attention is required. To avoid any health problems in the future, the continuous monitoring of groundwater is necessary. 
RASĀYAN J. Chem.

Vol. 12 | No. 4 |2235 - 2240| October - December | 2019

\section{REFERENCES}

1. L. Muthulakshmi, A. Ramu, N. Kannan, Indian J.Environ. Protec., 29(5), 435(2009).

2. R.K. Jaiwal, S. Mukherjee, J. Krishanamurthy, R. Saxena, Int. J. Remote Sens., 24(5),993(2003).

3. G. Katalakute, V. Wagh, D. Panaskar, S. Mukate, Nat. Resource Conser., 4(3), 35(2016).

4. DK Todd, Groundwater Hydrology, $2^{\text {nd }}$ edn, Wiley, New York (1980).

5. O. Apoto, T.N. Bruce, G. Darko, African J. Environ. Sci. Tech., 2(11), 354(2008).

6. E.O. Adaikpoh, G.E. Nwajei, J. E. Ogala, J. Appl. Sci. Environ. Manag., 9(3),5(2005).

7. J. Sirajudeen, S. Arul Manikadan, V. Manivel, World J. Pharma. Pharmaceut. Sci., 4(1),967(2014).

8. WHO, $2^{\text {nd }}$ end. Recommendation, WHO, Geneva, pp.180-181(1993)

9. S.S. Kale, A.K. Kadam, S. Kumar, N.J. Pawar, Environment Assess, 162(1-4), 327(2010).

10. G. Tamasi. R. Cini, Sci. Total Environ., 327,41(2014).

11. L. Belkhiril, L. Mounil, T.S. Narang, A. Tiri, Ground Water Sustain. Dev., 4, 12(2017).

12. S.V. Mohan, P. Nithila, S.J. Reddy, J. Environ. Sci. Health A ,31(2), 283(1996).

13. S.J. Reddy, Apple Academia Press Inc., India, (1995).

14. USEPA, Vol. 1, Human Health Evolution Manual (Part A), Washington (1989).

15. K. Brindha, G. Jagadeshan, L. Kalpana, L. Elango, Environ. Sci. Pollut. Res., 23, 8302(2016).

16. Planning Commission, (No ID: 4452) (2011).

17. UNDESA, Detailed Indicators 2012 Revision (2013).

18. ICMR, A Report of the Expert Group of ICMR, Hyderabad, India, pp. 3340(2009).

19. I. Lyulks, T. Ambalova, T. Vasiljeva, Netherlands, pp. 449-452, (2001).

20. S. Caeriom M.H. Costa, T.B. Ramos, F. Fernandes, N. Silveria, A. Coimbra, M. Painho, Ecol. Indicat., 5,155(2005).

[RJC-5259/2019] 